\title{
Comparative Analysis of Estimation Formula of Acid Dew Point for Different Flue Gas
}

\author{
Jinhui Song ${ }^{1, a}$, Jiahu Li ${ }^{2, b}$, Hui Yuan ${ }^{2, c,}{ }^{*}$, Zhongqiang Ren ${ }^{2, d}$ \\ ${ }^{1}$ Guangdong Electric Power Research Institute Energy technologies Ltd; \\ ${ }^{2}$ School of energy and power engineering, North China Electric Power University, Baoding, Hebei, \\ China \\ asongjinghui2006@163.com, b7954452@qq.com, c358303246@qq.com, d1696276900@qq.com \\ ${ }^{*}$ Corresponding author
}

Keywords: acid dew point, estimate, analysis

Abstract. Acid dew point is one of the important parameters in boiler design and operation. Its height is closely related to the flue gas temperature, boiler efficiency, coal consumption and the utilization of flue gas waste heat at the tail of the boiler. In this paper, from the point of view of the sulfur content of coal, the concentration of $\mathrm{SO}_{3}$ and the content of water vapor after burning, the common acid dew point estimation formula is used to estimate the corresponding acid dew point value, and the results are analyzed. The results show that the acid dew point and sulfur content coal, coal combustion and $\mathrm{SO}_{3}$ concentrations of water vapor basic related, compared with the A.G.Okkes formula, И.А.Bapahoba formula for estimation of the error is small, the former Soviet Union of the empirical formula of acid dew point value is low.

\section{Introduction}

Coal-fired boiler fuel contains a certain amount of sulfur, The flue gas by fuel combustion generated contains a certain amount of $\mathrm{SO}_{2}, \mathrm{SO}_{3}$ and water vapor. Under normal circumstances, coal-fired boiler flue gas $\mathrm{SO}_{3}$ volume of about 1 50ppm. When the temperature of flue gas is lower than $200^{\circ} \mathrm{C}, \mathrm{SO}_{3}$ and water vapor that in the flue gas condense into $\mathrm{H}_{2} \mathrm{SO}_{3}$ steam and $\mathrm{H}_{2} \mathrm{SO}_{4}$ steam, trace of $\mathrm{H}_{2} \mathrm{SO}_{4}$ steam makes the dew point temperature of flue gas significantly increased. According to the study shows that the exhaust gas temperature increased by $15 \sim 20^{\circ} \mathrm{C}$, the boiler thermal efficiency reduced by about $1 \%$, if the exhaust temperature is too low, it will cause the heating metal surface corrosion and affect the normal working of boiler. In order to avoid effectively the low temperature corrosion of the boiler, the economic exhaust gas temperature of the boiler should be kept within a certain range of the dew point of the flue gas. Therefore, the flue gas dew point temperature is predicted to reduce the low temperature corrosion and improve the boiler thermal efficiency has important practical significance.

In recent years, some scholars have begun to study the estimation model about acid dew point. Different acid dew point estimation models are proposed from different angles. These acid dew point estimation models have advantages and disadvantages. Each of the estimated models has different levels of acid dew point due to the different factors considered. Some scholars have compared and analyzed these estimation models, but did not consider the effect of the change of coal type and the content of coal components on the estimation of acid dew point. In this paper, the estimation model is evaluated in the case of coal. There are also some scholars start to study the influence of fly ash on acid dew point and make explanation for the low value of acid dew point in actual operation.

\section{The estimation of flue gas acid dew point}

\section{the estimation formula about flue gas acid dew point}

So far, many experts and scholars have done a lot of research on the estimation of acid dew point. Which can be divided into two categories: one is based on the Soviet Union and domestic scholars as the representative of a large number of power plant boiler unit based on the actual operation 
experience summed up the acid dew point empirical calculation model; the other is Western scholars as representative, based on acid dew point and The thermodynamic relations between the influencing factors and the semi- theoretical calculation model of experimental data were established. The first kind of research method is adaptable according to a large number of field experience data, but it can't reveal theoretically the relationship between acid dew point and its influencing factors. The second type of research method is mainly through the thermodynamic theoretical relationship and experimental data fit into acid dew point calculation model.Although its adaptability is not as good as the first method, but can reveal theoretically the relationship between acid dew point and its influencing factors, and thus more and more recognized by scholars ${ }^{[1]}$. These two types of estimates are shown in Table1.

Table 1 Acid Dew Point Estimation Formula

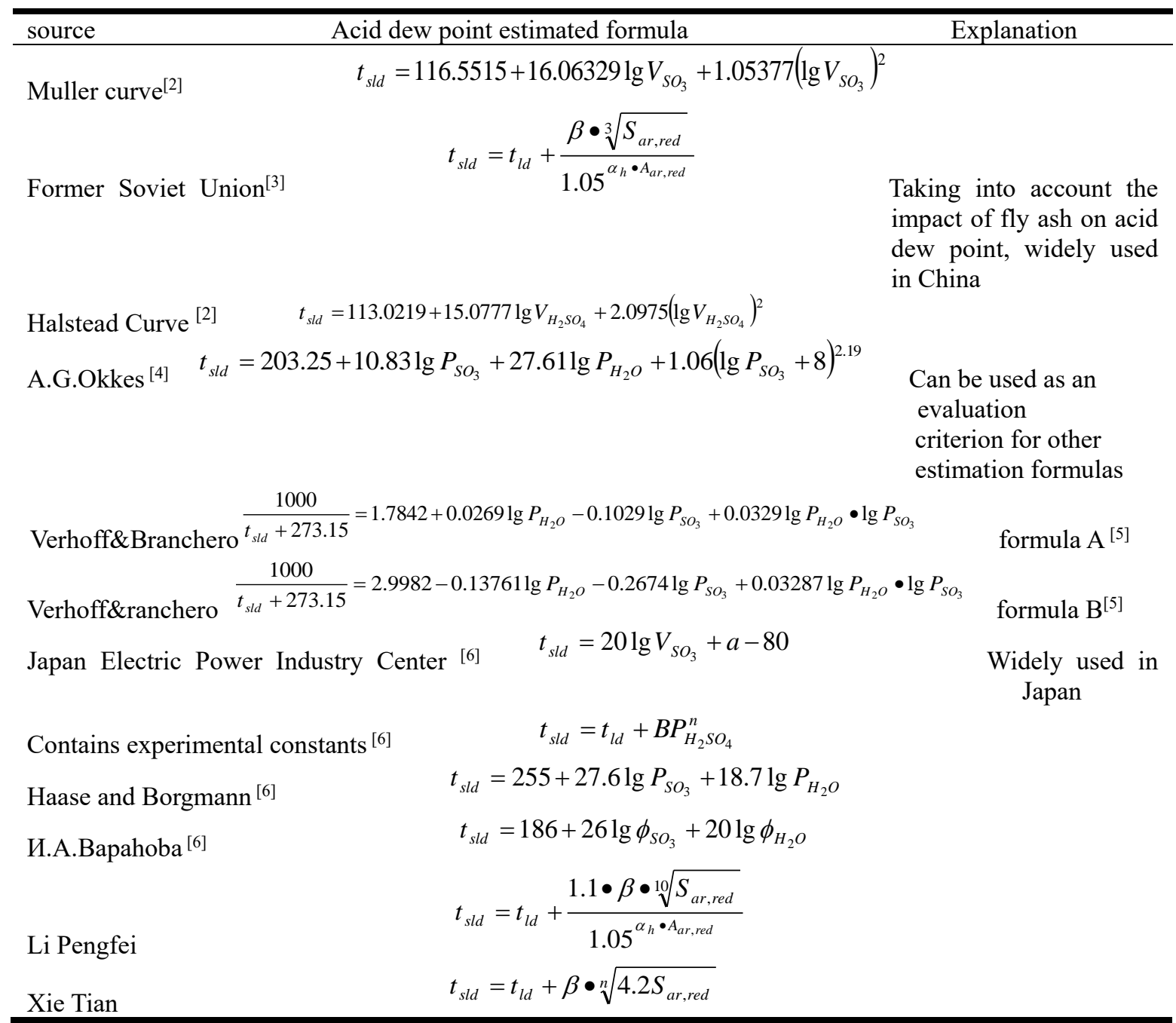

In addition to the above-mentioned more recognized estimates, foreign scholars have proposed other thermodynamic methods for calculating acid dew points. It includes numerical analysis, neural network and so on. For example, Bahadori proposed a dew point prediction tool based on the Van der Mundle determinant, which takes into account factors such as fuel type, $\mathrm{SO}_{3}$ concentration, and excess air coefficient.

ZareNezhad et al. on the basis of a large number of actual additions to the above-mentioned more recognized estimates, foreign scholars have proposed other methods of calculating the acid dew point of thermodynamics. It includes numerical analysis, neural network and so on. For example, Bahadori proposed a dew point prediction tool based on the Van der Mundle, which takes into account factors such as fuel type, $\mathrm{SO}_{3}$ concentration and excess air coefficient.ZareNezhad et al. Proposed a simulated neural network model to predict acid dew point based on a large number of 
actual operating data. But these methods have some limitations, and the need for some actual operating data. Such as $\mathrm{SO}_{3}$ concentration and water vapor concentration, etc. can not be obtained accurately.

\section{Analysis of Estimation Formula of Acid Dew Point for Flue Gas}

In this paper, eight kinds of acid dew point estimation methods are used to calculate the acid dew point values of ten kinds of typical coal (see Table 2) with different sulfur content.

Table 2 sulfur content of coal and combustion after flue gas SO3 concentration and water vapor content value

\begin{tabular}{|l|c|c|c|}
\hline kind of coal & Sulfur content (\%) & $\mathbf{S O}_{\mathbf{3}}$ content $(\mathbf{p p m})$ & Water vapor content (\%) \\
\hline Fengguang lignite & 0.2 & 3 & 15.1 \\
\hline Jiaozuo anthracite & 0.4 & 3.8 & 6 \\
\hline Longfeng washed coal & 0.5 & 6.4 & 7 \\
\hline Jinzhu Mountain anthracite & 0.6 & 5.6 & 6.1 \\
\hline Huainan bituminous coal & 0.7 & 6.6 & 8.5 \\
\hline Kailuan bituminous coal & 0.8 & 7.8 & 8.3 \\
\hline Yuanbaoshan lignite & 0.9 & 12.9 & 13.6 \\
\hline Fuxin bituminous coal & 1.0 & 11.7 & 9.7 \\
\hline Xuzhou bituminous coal & 1.2 & 10.8 & 6.3 \\
\hline Xishan lean coal & 1.3 & 11.6 & \\
\hline
\end{tabular}

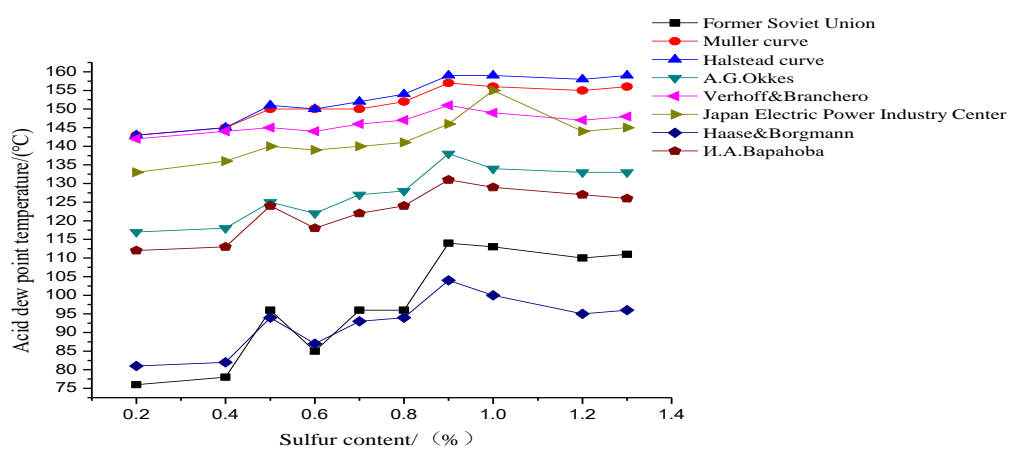

Fig.1 Curve of sulfur content in coal combustion on acid dew point

The formula proposed by Dutch scholar A.G.Okkes is obtained by the regression of the Muller curve. The equation takes into account both the influence of water vapor and the influence of $\mathrm{SO}_{3}$, and the calculated acid dew point data and the parameters of carbon, sulfur and excess air of the Mohr calculation, the difference between the two is less than $1.5^{\circ} \mathrm{C}$, is recognized as accuracy criteria of evaluation of other acid dew point estimation method .

Fig. 1 shows the effect of sulfur content on the acid dew point. It can be seen from the figure that with the change of sulfur content in coal, the change trend of acid dew point value obtained from the estimation formula of all acid dew is roughly the same. When the sulfur content was less than $0.8 \%$, the sulfur content was positively correlated with the acid dew point value. Because with the increase of the sulfur content of coal, the concentration of $\mathrm{SO}_{3}$ produced after combustion increases first and then increases. When the sulfur content is more than $0.8 \%$, the sulfur content is positively correlated with the acid dew point value. This is also because the concentration of $\mathrm{SO}_{3}$ in the flue showing the trend of increase first and then decrease. Compared with the A.G.Okkes formula curve, the Halstead curve, the former Soviet empirical formula and the Haase \& Borgmann formula have the greatest error. Among them, Halstead curve in the sulfur content is low, the maximum error up to 19\%.the estimates formula of Japan Electric Power Institute, И.A.Bapahoba formula and A.G.Okkes formula curve error is relatively small, the maximum error occurs in the coal when the sulfur content is high. The former Soviet Union empirical formula and the 
Haase\&Borgmann formula estimate the acid dew point is low.However, it is found from Fig. 1 that the law of change of the acid dew point with the change of the sulfur content of the coal is not obvious And it is not comprehensive to determine whether the accuracy of each estimation formula is only by comparing the change trend of the acid dew point with the sulfur content in the coal.Therefore, this paper also analyzes the accuracy of each estimation formula from the two factors that influence the acid dew point of $\mathrm{SO}_{3}$ concentration and water vapor content.

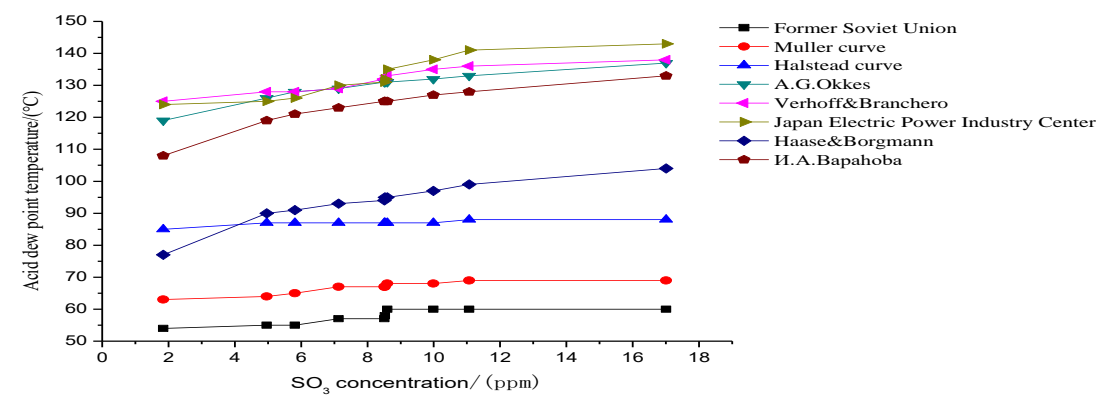

Fig.2 Curve of $\mathrm{SO}_{3}$ concentration on acid dew point when water vapor content is $9 \%$

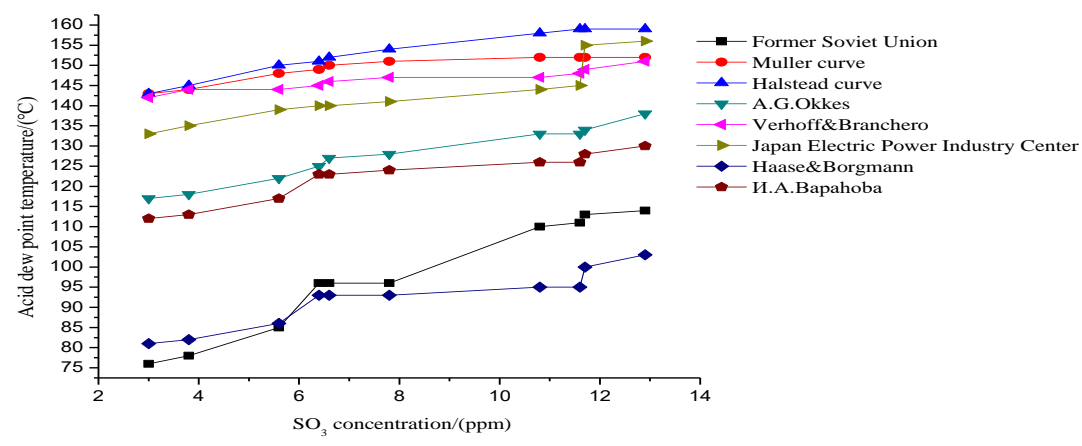

Fig. 3 Curve of $\mathrm{SO}_{3}$ concentration on acid dew point after ten kinds of coal combustion

Fig.2 shows the effect of $\mathrm{SO}_{3}$ concentration on the acid dew point when the water vapor content is $9 \%$. It can be seen from the figure,with the increase of $\mathrm{SO}_{3}$ concentration, the change trend of acid dew point is the same. When the $\mathrm{SO}_{3}$ concentration is less than $8.5 \mathrm{ppm}$, the acid dew point value is positively correlated with the $\mathrm{SO}_{3}$ concentration and the increase rate is more faster. When the concentration of $\mathrm{SO}_{3}$ is more than $8.5 \mathrm{ppm}$, the acid dew point value is positively correlated with $\mathrm{SO}_{3}$ concentration but the increase rate is slow. Compared with the A.G.Okkes curve, the error of the former Soviet empirical formula and the Muller curve is the largest, and the former Soviet empirical formula has a maximum error of $56 \%$ at low concentration. The Verhoff \& Branchero formula has less error than the A.G.Okkes formula curve. This comparison is only from the content of water vapor keep constant to analyze the accuracy of the formula, but taking into account the actual situation in the power plant every day to burn different types of coal flue gas water content is changing, Therefore, the calculated $\mathrm{SO}_{3}$ concentration and the corresponding acid dew point values of the ten kinds of coal combustion in this paper are used to analyze the change trend of acid dew point with $\mathrm{SO}_{3}$ concentration in the actual operation.

Fig. 3 shows the influence of $\mathrm{SO}_{3}$ concentration on acid dew point after ten coal combustion. It can be seen from the figure that the acid dew point has a positive correlation with the $\mathrm{SO}_{3}$ concentration in the flue gas after coal combustion but increase slowly. Although the content of water vapor that generated by the different types of coal burning after is different, increasing the concentration of $\mathrm{SO}_{3}$ in the flue gas so that the partial pressure is increased that leads acid dew point also increase. Compared with the A.G.Okkes formula, the Halstead curve and the Haase \& Borgmann formula have a large error of up to 20\%. Japan Electric Power Research Institute estimates, И.A.Bapahoba formula error is small. The empirical formula of the former Soviet Union 
and the Haass \& Borgmann formula are low. Muller curves calculate the acid dew point value is high.

By comparing Fig. 2 and Fig. 3, the acid dew point value increases as the $\mathrm{SO}_{3}$ concentration increases. Former Soviet empirical formula, Haass \& Borgmann formula and И.A.Bapahoba formula's acid dew point value is low. Japan Electric Power Research Institute estimated formula and Verhoff \& Branchero estimated formula on the Acid dew point value is high. The former Soviet Union empirical formula on the calculated value of acid dew point is lowest, because it is a large number of measured data from the power station and take into account the impact of fly ash on acid dew point, so it is closer with the actual value of acid dew point.

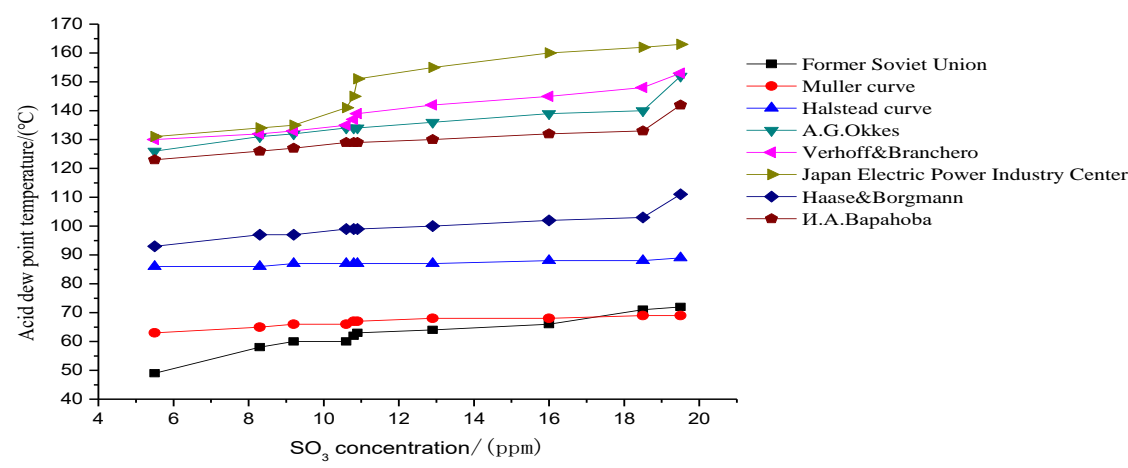

Fig. 4 Effect of water vapor content on acid dew point when SO3 concentration is $10 \mathrm{ppm}$

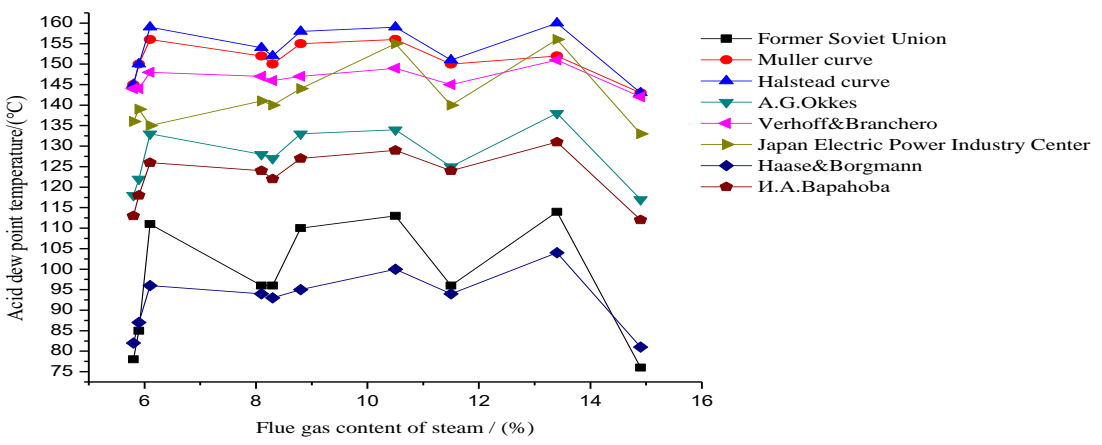

Fig.5 Curve of water vapor concentration on acid dew point after ten kinds of coal combustion

Fig. 4 shows the effect of water vapor content on the acid dew point at $\mathrm{SO}_{3}$ concentration is 10 ppm. Due to the Muller curve, the Halstead curve does not take into account the effects of water vapor, and the acid dew point does not change when the content of water vapor changes. With the increase of content of water vapor, the acid dew point calculated by each estimation formula showed the same trend with the increase of water vapor content. When the content of water vapor is less than $11 \%$, the content of water vapor is positively correlated with the acid dew point and grows faster. When the water vapor content is greater than $11 \%$, the acid dew point rises slowly. Compared with the A.G.Okkes formula, the Japan Electric Power Research Institute estimated the formula, Verhoff \& Branchero estimated the calculated value is high and the others are low. The content of water vapor in the flue gas and the corresponding acid dew point values were calculated in this paper. So as to study the change trend of acid dew point with the increase of water vapor content when $\mathrm{SO}_{3}$ concentration is different.

Fig. 5 shows the influence of the concentration of water vapor on the acid dew point after ten coal combustion. As can be seen from the figure, with the increase in the percentage of water vapor in the flue gas, all the acid dew point estimated formula calculated from the acid dew point value of the trend is roughly the same. When the content of water vapor is less than $8.5 \%$, The relationship 
between the acid dew point and the percentage of water vapor is first positive and then negatively correlated, which is because the concentration of $\mathrm{SO}_{3}$ in flue gas increases first and then decreases, and the concentration of sulfuric acid increases first and then decreases. When the content of water vapor is more than $8.5 \%$, the acid dew point is first positive and then negatively correlated with the percentage of water vapor, which is also due to the concentration of $\mathrm{SO}_{3}$ in flue gas increases first, then decreases and then increases.Compared with the A.G.Okkes formula curve, Halstead curve, Haase and Borgmann are the most error. Among them, the Halstead curve has a higher error in high content of water vapor, up to $33 \%$. И. A.Bapahoba formula, the former Soviet Union, Haase and Borgmann empirical formula's estimated value is low.

Compared with Fig. 4 and Fig. 5, the trend of the theoretical calculation is different from that of the ten kinds of coal calculated by the increase of the content of water vapor. The former set the concentration of $\mathrm{SO}_{3}$ in the flue gas as the fixed value, while the latter the concentration of $\mathrm{SO}_{3}$ increased first, then decreased and then increased.Compared with the A.G.Okkes formula, the estimate of the acid dew point of the И.A.Bapahoba formula is close to that. The former Soviet Union empirical formula is low.

\section{Conclusion}

(1) From the analysis of the sulfur content of coal, we can see that the estimated formula of Japan Electric Power Research Institute, И.A.Bapahoba formula and A.G.Okkes formula curve error is relatively small, the former Soviet Union empirical formula to estimate the acid dew point is relatively low.

(2) Analysis of $\mathrm{SO}_{3}$ concentration from flue gas, Compared with the A.G.Okkes formula, the.A.Bapahoba formula and Verhoff\&amp \& Branchero formula of acid dew point calculation error is small. The acid dew point value calculated by the empirical formula of the former Soviet Union is minimum.

(3) From the analysis of the content of water vapor in the flue gas, compared with the A.G.Okkes formula, the estimated value of acid dew point of И.A.Bapahoba formula is close with it. The estimated value of acid dew point of the former Soviet empirical formula is the lowest.

\section{Acknowledgements}

This paper is one of the phased results of the research and development of low temperature and low temperature heat and dust control of supercritical boiler (GDKJXM00000004)in China Southern Power Grid Co., Ltd.

\section{References}

[1] Junkai Feng, Youting Shen editor. Boiler theory and calculation [M]. Beijing: Science Press, 1992: 378-379(in chinese).

[2] Ming-sheng Jia,Chang-ming Ling.Factors of Affecting the Flue Gas Acid Dew Point Temperature and its Way of Calculation[J].Industrial Boilers 2003,6:31-35(in chinese).

[3] Junkai Feng, Youting Shen editor. Boiler theory and calculation [M]. Beijing: Science Press, 1992: 378-379(in chinese).

[4] A.G.Okkes, Badge B.V.Get Acid Dew Point of Flue Gas[J].Hydrocarbon Processing, 1987 (7):53-55.

[5] Verhoff.F.H,Banchero.J.T.Predicting Dew Point of Flue Gases [J]. Chem. Eng. Prog, 1974, 70(8):71-72.

[6] Zhi-Yong Tang, Bao-sheng Jin,Ke-qin Sun et al.he contrast and evaluation of the calculation formulas of acid dew point temperature of the flue gas after the WFGD [J].Journal of Power Engineering,2005,25(Sup.):18-21(in chinese). 